\title{
Resolution on the E-commerce Domain Name Dispute on the Next Generation Internet
}

\author{
YingZhou ${ }^{1, \text { a }}$, Pancheng $\mathrm{Li}^{2, \mathrm{~b}}$ \\ ${ }^{1}$ JiangXi Police Institute, Nanchang, JiangXi, China

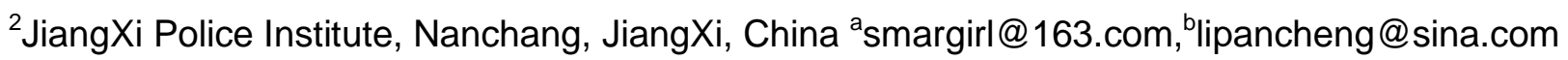

Keywords: Domain Name, Conflict, Register

\begin{abstract}
Domain name system is a new kind of network addressing technology which produces when Internet technology develops on a certain historical stage ,while the domain name will no longer be a pure technical symbols when people have some benefit through the domain name .Disputes become emerging endlessly associate with domain name. Conflict and benefit with domain name dispute are discussed on the basis of above in the article.
\end{abstract}

\section{The Reality Cause of Domain Name Disputes}

In the early design and practice of domain are not of any commerce and value. When the domain is used for business and have the business marking feature, the possibility of interest conflicts which ware produced between identical or similar trade marks right holders .In sense, Domain name logoes will have the conflicts with trademarks, trade names and other trade marks, Due to technical features domain names globally unique and existing prior rights to the domain name registration system is not reviewed with lack of effective integration between related systems, conflict between domain name rights and trade mark rights in the interests is inevitable. Since business value of domain name is payed attention by people all kinds of disputes arising from the registration and use of domain names are endless. Generally, similar approximation of the registration of the domain name and other people's business such as trademarks, trade names is the cause of domain name disputes. To sum up, domain name disputes mainly occurs for several reasons:

Wide Business Applications of Domain Name and Business Value Highlights. Domain name character with an identity and domain name business application form the basis in reality that cause interest conflict between network domain name registration applicant or holder and the traditional commercial mark right holder. With the development of e-commerce, business organizations have become increasingly aware of creating a Web site to serve as a basic means of developing e-commerce potential. And when applying for a domain name, they try to use their legally obtained trademarks, trade names and other special symbols of words to attract consumers and potential consumers so that they expand the reputation further on the Internet and grow the business. But in the case of no registered trademarks or low popularity of registered trademarks of their own ,some others will put a existing or a certain well-known trademark registration as their domain name to improve access of the Web site. This is the inevitable result of the profit-driven, inevitably leading to conflict between domain names and traditional trade marks.

Lack of Effective Coordination for Domain Name Registration System and the Legal System of Trade Mark Rights. As domain name belongs to a new technology product now, the nature and status of which are unable to determine legally, registered organization set the existing domain name registration system according to convenient technology, easy registrationore and network application popularization. On the one hand ,the policy is conducive to the popularity of the domain name registration promotion and quantitative development,on the other,it causes 
uncertainty of domain name rights of certain interests in law,which exacerbate the domain conflict between domain name and the traditional commercial mark right.

Conflicts between Global Uniqueness of Domain Name and the Geography of Traditional Trade Mark Rights. The conflicts between global uniqueness of domain name and the geography of traditional trade mark rights constitute technical basis of a domain name applicant or holder and traditional commercial mark rights. Under the current legal framework of intellectual property all over the world, traditional trade mark rights have a certain geographical restrictions. In the domain of its registration, they generally cannot be protected. But domain name has a worldwide unique based on the technical requirements. Therefore, the domain name applicant or holder may face the charge from all worldwide traditional business mark rights. Because there are the causes of domain name disputes, the three parties mentioned of above does not cover all causes of domain name disputes. But this discussion is meaningful, because the domain name dispute resolution and the perfection of relevant systems must be considered based on the root causes of domain name disputes so that the resolution of domain name dispute can be a fair and equitable balance between the interests of all parties with better prospect of related systems .

\section{Analysis for Types of Domain Name Disputes}

From the perspective of domain name dispute form, domain name dispute can be divided into three categories:

The first is the " Malicious infringement " domain name disputes, also known as " Registered " domain name disputes, which is the behavior that someone use those specified trademark, trade names and names with high visibility and impact as domain names and try to make profit by selling. Such domain name registrar does not normally use the domain name and only register the domain name for profit.

The second is "unfair competition " domain name disputes,which is different from " Registered " domain name. Register themselves have no any rights for traditional trade mark of of the domain name core character . While selling mark rights is not for the purpose of profit, but for taking the bus of good reputation of commercial marks.

The third category ,"having prior rights " domain name disputes, mainly refers that the dispute parties have prior rights on the same domain name characters.

\section{Analysis for Typical Behavior of Domain Name Disputes}

Unfair Competition of Domain Name Disputes. Domain name dispute constitutes such circumstances should accord two conditions: First, when its core character parts of domain name are only used for commercial purpose, they come practical effect of business logo to have the possibility of interest conflicts with the other commercial mark rights .Second, the purpose registe registered the domain name is not only used for resolving IP addresses, but also used for commercial purpose with utilizing other's good reputation. In other words, the domain name registrant compete unfairly on the subjective. When domain name signed up by someone is used for a commercial purpose with same or similar commercial marks of others, two kinds of results were predicted by Business logo rights holder: One is that domain names confuse wiith trademarks, trade names to form the cause of counterfeiting. The other Is that domain name "weakened" popularity of trademark, trade name, business sign visibility and attenuated sign effects of the business mark and contact of right holders or disparage the reputation of a trade mark and rights of holders. 
"Malicious Infringement" Domain Name Disputes-Cybersquatting. Under domain name dispute resolution provisions of China Internet network information center , what meets the following conditions constitute cybersquatting: domain name that are complainted are the same as complainant's name or logo with confusingly similar; the domain name holders are complainted do not have the legal preceding rights for domain name or its major part ; the holder complainted registered and used the domain name with malicious intent. For general trademark, whether the registration of a domain name registrant are identified cybersquatting, which is the core elements that whether the applicant was subjectively malicious. According to the relevant report of the world intellectual property organization and the rule of the national Internet centre, a identification of malicious Registration Act should be considered by the following main factors: domain name holders registered multiple domain names in order to sell, lease or transfer domain name; Domain name registrant attempts to distract consumers from all trademarks, trade names or domain names, or other Web pages to transfer on their web pages or other online services; the purpose of domain name registration is for damaging business competitor's goodwill; Domain name holder register to stop others from registering with trademarks, trade names.

Cybersquatting is an act in an infringement sense, rather than conflict of interest on legal rights . Principles of the cybersquatting law will protect the legal rights of the infringed persons. In fact, since the most basic rights owned by the domain name owner, the right to the domain name resolution, originated from contract claims. When the contract have the actual existence of illegal purposes, according to the theory of contract law,domain name rights become ineffective. So we can understand why national courts and domain name registries have a consistent attitude to behavior of domain names registered, which decides that the registration act infringes others' legal rights.

\section{Conclusion}

As a technical means of network domain name itself is constituted by specific character, digital and symbolic.It does not in itself constitute rights and may only become the object of rights. The existing legal framework should actively respond to the new issues that arise under the condition of network technology and timely local and regulate the related rights with adjusting the different domain name disputes according to the established legal principles to get equal protection of the interests of all parties. Only in this way we can resolve all disputes reasonably and equitably in connection with the domain name to protect the legitimate interests of various subjects of rights and to maintain order in the network environment, further promoting and advancing Internet-based economic, scientific, technological and cultural development and prosperity.

\section{References}

[1] Lili Chen. Online advertising acts of unfair competition and its regulation of law [D].Harbing:HeiLongJiang college, 2013.

[2] Jihua Deng. Unfair competition in e-commerce and its regulation [J].Heilongjiang Technology Information, 2014(24).

[3] GangXie. Measures and rules for the prevention of domain name disputes[j]. Software Review,2008

[4] DenghuiShang.Research on the legal regulation of anti-unfair competition of the network new unfair competition behavior[j]. Market Modernization,2013 